\title{
Autosomal dominant anterior polar cataracts associated with a familial 2;14 translocation
}

\author{
T MOROSS*, S S VAITHILINGAM†, S STYLES $\ddagger$, AND H ALLEN GARDNER*
}

From * the Cytogenetics Unit, Department of Pathology, Toronto General Hospital, Toronto, Ontario; $\dagger 74$ Golden Avenue, South Porcupine, Ontario; and $\ddagger$ the Department of Medical Genetics, Royal Jubilee Hospital, Victoria, British Columbia, Canada.

SUMMARY We describe a family in which autosomal dominant anterior polar cataracts are segreso gating in four members over three generations with an apparently balanced reciprocal translocation between chromosomes 2 and 14. We conclude that altered function of a gene or genes on chromo-is somes 2 or 14 are important in the embryological development of the lens.

Anterior polar cataracts appear as small opacities on the anterior surface of the lens and usually do not interfere with vision. They may arise de nove or be inherited in either an autosomal dominant, autosomal recessive, or $\mathrm{X}$ linked fashion. ${ }^{1}$ Three mechanisms are postulated for their formation.

(1) Imperfect separation of the lens from the surface ectoderm during the fifth week of embryological development.

(2) Secondary changes to the epithelial cells with the formation of an abnormal mass in the region of the anterior pole.

(3) Incomplete resorption of blood vessels and mesoderm at the anterior pole of the embryonic lens. ${ }^{2}$

No chromosomal abnormality has yet been described in association wirh congenital cataracts. ${ }^{3}$ We report a family in which congenital anterior polar cataracts and a constitutional chromosomal translocation $t(2 ; 14)(\mathrm{p} 25 ; \mathrm{q} 24)$ are segregating together.

\section{Case reports}

The proband, born prematurely on 29.5 .74 by normal vaginal delivery, was referred for cytogenetic investigation of congenital anterior polar cataracts diagnosed on routine examination. There were no other phenotypic abnormalities. Cytogenetic studies performed on peripheral blood showed an apparently balanced reciprocal translocation between chromosomes 2 and 14 with breakpoints at p25 and q24 respectively (fig 1). His sister (IV.6), mother (III.6), and maternal grandmother (II.2) also had congenital cataracts and also carried the translocation. No other

Received for publication 11 June 1983.

Accepted for publication 15 June 1983.

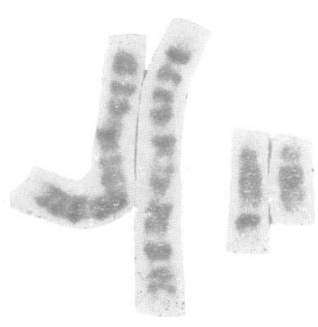

FIG 1 Partial karyotype of GTG banded chromosomes 2 and 14 showing the reciprocal translocation $t(2 ; 14)(p 25 ; q 24)$. The normal chromosome is on the left of each pair.

congenital abnormalities or handicaps were present. The grandmother's sister (II.1) had neither the translocation nor the cataracts. Eye examinations of her children and grandchildren showed normal lenses. Chromosome studies were felt to be unnecessary in view of the normal chromosomes of II.1. Thus no family member with normal lenses had the translocation and no family member with a normal karyotype had the cataracts (fig 2). The uncle (III.7) declined $\sigma$ to be examined. In no instance did the cataracts impair vision or require surgery.

The maternal grandmother had had three or four spontaneous abortions, presumably because of cytogenetically unbalanced zygotes although the products of conception had not been examined. The great-aunt (II.1) had two stillborn daughters (III.1 and III.2) who were described as being phenotypically normal. No explanation was given 


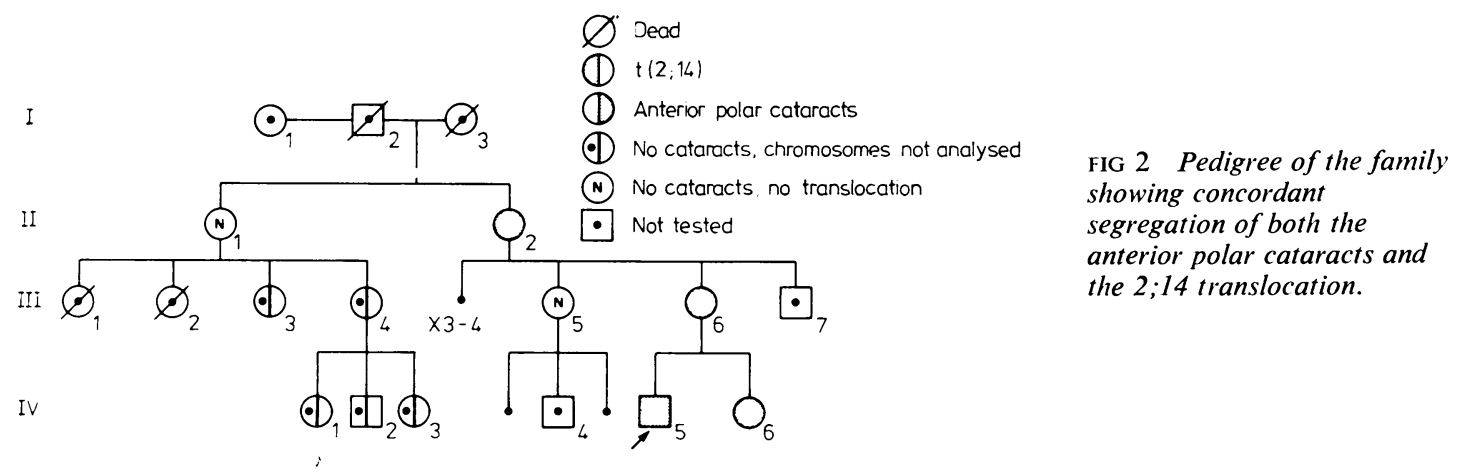

for the deaths, but she subsequently had two liveborn normal daughters. The aunt (III.5) had two spontaneous miscarriages. Obviously the familial translocation played no part in either these miscarriages or the stillbirths as the mothers were cytogenetically normal.

\section{Discussion}

Congenital cataracts are one of the most common major abnormalities of the eye. Familial types constitute 8 to $23 \% 1$ and various modes of transmission (autosomal dominant, autosomal recessive, and $\mathrm{X}$ linked) have been described. Autosomal dominant is the most common pattern of inheritance; penetrance of the gene is complete and expression of the gene more or less uniform. ${ }^{1}$

The only associated gene marker is that of the Duffy blood group located on chromosome 1 and linked to zonular pulverulent cataracts. ${ }^{4}$ No other associations have been made although it seems certain that as many as eight to 12 gene loci, possibly on as many chromosomes, may be involved in the autosomal dominant types. ${ }^{1}$

Cataracts have been described as a manifestation of well recognised cytogenetic syndromes, for example, trisomies for 18 and 21 , long arm deletions of 18 and 21 , short arm deletion of 18 , and Roberts syndrome. ${ }^{5}$ However, they have not been associated with a chromosome disorder specific for the cataract.

Anterior polar cataracts constitute about $3 \%$ of congenital cataracts. ${ }^{6}$ in most cases they are hereditary and the inheritance is frequently dominant. Occasionally, however, they may be sporadic. ${ }^{1}$ No gene linkage or chromosomal abnormality has been reported associated with anterior polar cataracts.

The cataracts in this family occurred in four people over three generations and follow an autosomal dominant pattern of inheritance. It is segre- gating concordantly with a familial $2 ; 14$ translocation. It seems reasonable to conclude that there is a cause-effect relationship.

It is possible that altered function of a gene or genes on chromosomes 2 or 14 has resulted in abnormal lens development. Position effect is one explanation and altered function owing to a small deletion at either $2 \mathrm{p} 25$ or $14 \mathrm{q} 24$ is another. Acid phosphatase 1 is located at the former locus; at the latter no firm assessment has been made although tryptophanyl-t RNA synthetase is located distal to $14 \mathrm{q} 21 .{ }^{4}$ We have not attempted any linkage analysis.

The authors are grateful to $\mathrm{Dr} \mathbf{H} \mathbf{J}$ de Haan for referring the patient, and for the excellent assistance given by Maggie Wing, technologist, Patti Cork, typist, and Peter Honor, medical artist.

\section{References}

1 Merin S. Congenital cataracts. In: Goldberg MF, ed. Genetic and metabolic eye disease. Boston: Little, Brown, and Co, 1974:337-55.

2 Warkany J. Congenital malformations. Notes and comments. Chicago: Year Book Medical Publishers, 1971: 372-3.

3 Mostafa MSE, Temtamy S, El-Gammal MY, Abdel Sayed SI, Abdel-Salem M, El-Barondy R. Genetic studies of congenital cataract. Metab Pediatr Ophthalmol $1982 ; 5: 233-42$.

4 Cook PJL, Hamerton JL. Report of the committee on genetic constitution of chromosome 1. Edinburgh conference. Human gene mapping 5. Birth Defects 1979; XV:9-20.

${ }^{5}$ Smith DW. Recognizable patterns of human malformation. 2nd ed. Philadelphia: Saunders, 1976:480.

${ }^{6}$ Francois J. Congenital cataracts. Assen, Netherlands: Royal Van Gorcum, 1963:101.

Correspondence and requests for reprints to Dr H Allen Gardner, Cytogenetics Unit, Department of Pathology, Toronto General Hospital, 101 College Street, EC3-301, Toronto, Ontario. Canada M5G 1L7. 